\title{
Training in Scotland During COVID-19: The Dental Core Trainee Perspective
}

ISSN: 2637-7764

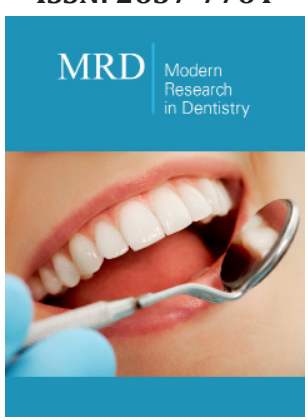

*Corresponding author: $\mathrm{N}$ McGrath, OMFS Ninewells, Dental Core Trainee 3, Ninewells Hospital and Dundee University Medical School, Scotland

\section{Submission: 海 August 28, 2020}

Published: 皆 September 11, 2020

Volume 5 - Issue 3

How to cite this article: N McGrath, S Dolan, J Sweeney, E Rae, S Laverick. Training in Scotland During COVID-19: The Dental Core Trainee Perspective. Mod Res Dent. 5(4). MRD. 000616. 2020. DOI: 10.31031/MRD.2020.05.000616

Copyright@ N McGrath, This article is distributed under the terms of the Creative Commons Attribution 4.0 International License, which permits unrestricted use and redistribution provided that the original author and source are credited.

\section{N McGrathi*, S Dolan², J Sweeney², E Rae ${ }^{1}$, and S Laverick ${ }^{3}$}

${ }^{1}$ OMFS Ninewells, Dental Core Trainee 3, Ninewells Hospital and Dundee University Medical School, Scotland

${ }^{2}$ OMFS Ninewells, Dental Core Trainee 2, Ninewells Hospital and Dundee University Medical School, Scotland

${ }^{3}$ OMFS Ninewells, Consultant, Ninewells Hospital and Dundee University Medical School, Scotland

\section{Opinion}

The first confirmed case of COVID-19 in Ninewells hospital in Dundee was on the $2^{\text {nd }}$ March 2020, the first ventilated case was $20^{\text {th }}$ March 2020. The Oral and Maxillofacial department (OMFS) quickly changed the daily routine to set up for the global pandemic. The reduction of footfall within the hospital and reduced contact with routine patients was advised by the Government. Published evidence stated that surgeons and physicians who, by the nature of their practice, have close face to face contact are at high risk of contracting COVID-19. OMFS fall within this category. Our department cancelled all non-essential clinics. Decision on cancellations was dependent on diagnoses and urgency of referral. OMFS department undertakes aerosol generating procedures; under guidance all dento-alveolar treatment was cancelled. Telephone consultations with these patients, allowed advice to patients in relation to emergency treatment during COVID times.

Consultants determined which oncology patients required face-to-face reviews. This decision was made on the basis of length of time post-operatively and initial diagnosis. The patients that did not require face-to-face review initially received a telephone consultation, dental core trainees (DCTs) undertook these telephone consultations. If any concerns were raised an "attend anywhere" review was arranged. A DCT became the main lead in "attend anywhere" using the "Near Me" software. Near me has been approved as a secure form of video consultations by the Scottish Government. This programme allowed virtual clinics to be carried out from the patients' own home, if further concerns were raised the patient attended for a face-to-face review. Clinical Leads of surgical specialities determined a pathway for emergency patients (Figure 1). New pathways were created to take into consideration the COVID status of each patient. Although initially it seemed to be complex, it became the responsibility of the DCTs to take control of the pathway and make it manageable and safe for patients and clinicians. The department constructed SBARS (situation, background, assessment, and review) on surgical procedures for oral cancer and skin cancer. This recommended the continuation of ablative surgery where clear margins were expected and that should not be delayed due to it being time sensitive. The aim was to reduce complexity of surgery, therefore avoiding a tracheostomy, reduce need for HDU/ICU, reduce in-patient stay, and reduce the duration of surgery i.e local flaps preferred over free flaps. Due to low numbers in Scotland during the COVID pandemic oral squamous cell carcinomas continued to be treated throughout this time. Skin cancer surgery was deferred with the exception of highly symptomatic lesions and those with rapid growth. All melanomas, proven high risk SCC and only BCC of considerable size or high-risk anatomical site therefore were addressed. 


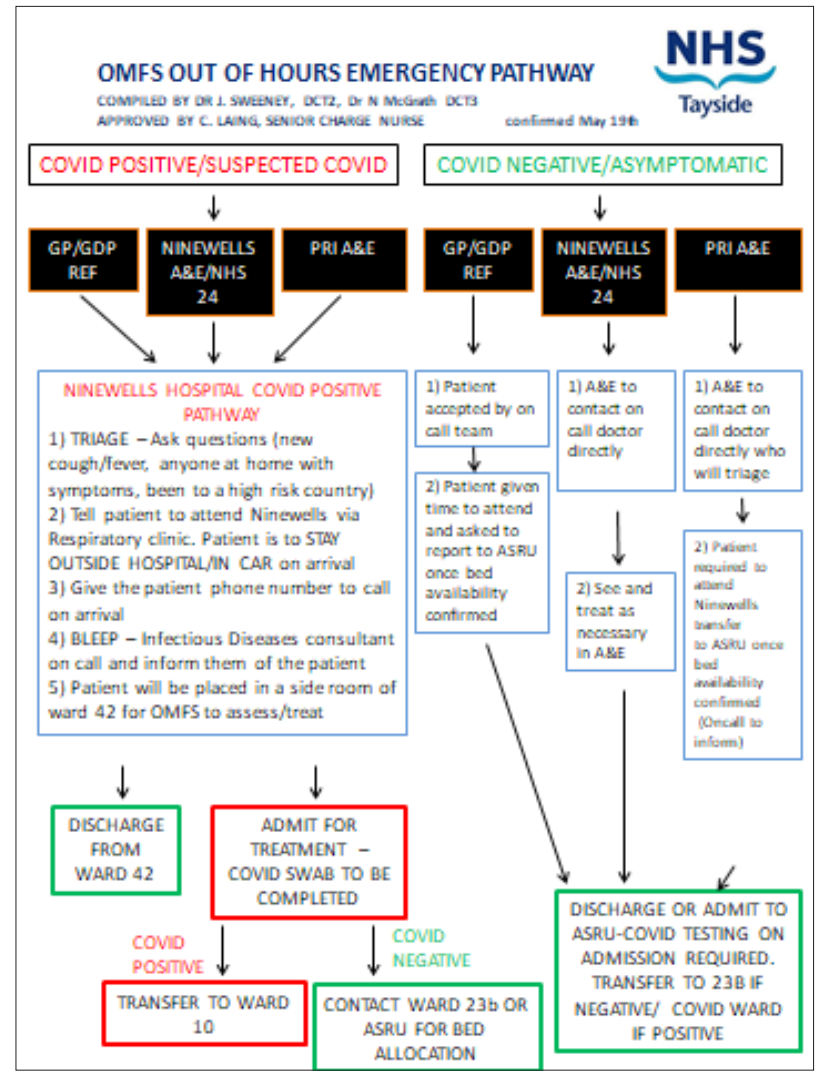

Figure 1: Current OMFS Emergency pathway.

Reduction in staff allowed social distancing within the work place. Members of staff attended refresher courses for redeployment. The orthognathic consultant retrained in head and neck oncology surgery, to allow for the change in demands of the department. It allowed for the potential cover of consultant shortage to continue the treatment of urgent cases. An ongoing trauma audit within the department has noted a reduction in trauma and a change in location of trauma incidents. Prior to COVID many trauma incidents occurred within or close proximity to public houses and nightclubs. The trauma seen during COVID has been mostly drug related or elderly individuals falling within their home. Fewer dental abscesses required admission which may be related to the efficient set up of the emergency dental care centres within the area.

Following this pandemic, it will take time for the NHS to recover. We aim to review our current patients as soon as reasonably possible. We expect as GDPs and GMPs return to normality there will be an increase of referrals.
Scotland had a lower number of COVID cases in comparison to other places within the UK, therefore redeployment was not required. Dental Core Trainees during this time were able to develop new skills. The DCTs became adept at telephone consultations. Focusing on adequate history taking and prioritising the urgency of appointment required. There is potential for this to become the standard of care, allowing the Dental Core Trainees to have the confidence to carry these out meticulously. Due to redeployment of the OMFS FY Doctor, the Dental Core Trainees took responsibility for the ongoing inpatient care. These skills will undoubtable help us in our future career, as it has improved our knowledge on medically compromised patients. Although our training year is not what we expected as Dental Core Trainees, during this time we have gained an invaluable experience that our future careers, and patients, will benefit from. 